\title{
Precipitation extremes in the Mediterranean region and associated upper-level synoptic-scale flow structures
}

\author{
Andrea Toreti ${ }^{1} \cdot$ Paraskevi Giannakaki $^{2}$ - Olivia Martius ${ }^{2}$
}

Received: 19 May 2014 / Accepted: 1 December 2015 / Published online: 22 December 2015

(C) The Author(s) 2015. This article is published with open access at Springerlink.com

\begin{abstract}
A non-stationary analysis of daily precipitation extremes over the Mediterranean region and the associated upper-level atmospheric dynamics is presented for autumn, winter and spring. An Extreme Value Theory approach is applied to identify homogeneous areas in terms of precipitation extremes and to characterise the spatio-temporal behaviour of precipitation extremes. Results reveal a high spatial variability of extremes in the region as a whole, while the eastern Mediterranean shows a lower variability compared to the western part. The temporal variability of the estimated 5-year return levels also varies significantly across the basin especially in autumn. The synoptic-scale flow structures associated with these extreme events are then investigated. Significant upper-level flow anomalies in the form of troughs and cut-offs are found for all regions/ seasons. Moreover, in many areas the associated low-level flow is directed against the local topography pointing to the relevant role of orographic lifting. Finally, significant precursor signals, 2-3 days before the events, are identified for most of the areas.
\end{abstract}

Keywords Precipitation extremes · Potential vorticity · Mediterranean

Electronic supplementary material The online version of this article (doi:10.1007/s00382-015-2942-1) contains supplementary material, which is available to authorized users.

Andrea Toreti

andrea.toreti@jrc.ec.europa.eu

European Commission, Joint Research Centre, Ispra, Italy

2 Institute of Geography, Oeschger Centre for Climate Change Research, University of Bern, Bern, Switzerland

\section{Introduction}

The Mediterranean region has been identified as a climate change hot-spot (Giorgi 2006) with model projections showing a significant increase of seasonal mean temperature (Knutti and Sedláček 2012) as well as an intensification of related extremes (Kharin et al. 2013). In addition a decrease of seasonal precipitation (Knutti and Sedláček 2012) and an intensification of precipitation extremes (Toreti et al. 2013) are projected. However, higher uncertainties and seasonal differences characterise the future evolution of precipitation and its extremes over the region (e.g., Toreti et al. 2013). Since precipitation extremes have a profound impact on both natural and human systems and the Mediterranean region is known to be exposed and vulnerable (Lionello et al. 2012), a better understanding (as well as a better characterisation) of those events is upmost. Thus, potential future changes can be better identified, described and interpreted.

When modelling extreme events such as heavy precipitation events, it is important to take into account their spatiotemporal evolution (Davison et al. 2012) as the statistical characterisation of those events greatly benefits from taking into account all available information. This can be done, for instance, by jointly analysing extremes at several locations belonging to the same homogeneous area, in terms of the behaviour of the extremes, and not just at one observation point (Naveau et al. 2014). The spatial complexity of the Mediterranean region (Lionello et al. 2012) and the associated complexity of the dynamical and physical processes that cause extreme precipitation, however, translate into the impossibility of analysing the region as a whole. This is reflected in numerous studies focusing on the description of the synoptic systems that trigger extreme precipitation events in various sub-regions of the Mediterranean. 
Substantial variability is found between the western and the eastern Mediterranean but also on much smaller spatial scales due to the interaction of synoptic-scale and meso-scale processes triggering extreme precipitation (e.g., Doswell III et al. 1998).

In this study we focus on the role of synoptic-scale systems. For extreme precipitation to occur, sustained transport of moist air into the precipitation area is needed as well as lifting of the moist air. Synoptic-systems ensure an adequate moisture transport and contribute to the lifting of moist air. The eastward propagation of an upper-level positive potential vorticity (PV) anomaly, e.g. a north-south oriented trough or a cut-off, results in quasi-geostrophic lifting on the eastern flank of the anomaly (Hoskins et al. 1985). The upper-level anomaly is associated with a cyclonic flow anomaly that can reach the lower-troposphere (Hoskins et al. 1985). When this flow is directed against a topographical barrier, precipitation extremes are favoured (e.g. Massacand et al. 1998). Further on, an upper-level north-south oriented trough is associated with southerly flow along its eastern flank and this can result in lifting along the northsouth sloping isentropes (Hoskins et al. 1985). In addition, the destabilization of the atmosphere by the upperlevel positive anomaly (Hoskins et al. 1985) can result in enhanced convection (e.g., Funatsu and Waugh 2008).

Numerous papers have found a close linkage between upper-level flow structures and extreme precipitation events in different Mediterranean regions. Toreti et al. (2010) characterised precipitation extremes at Mediterranean coastal sites from 1950 to 2006 and identified, both for the western and the eastern parts of the Basin, three main mid-troposphere anomalous configurations. Nuissier et al. (2008) and Ducroq et al. (2008) analysed three extreme precipitation events that occurred in southern France and highlighted: an almost stationary synoptic configuration with a deep cyclonic circulation extending from the North Atlantic to the western edge of the Mediterranean and a ridge over central Europe. Similar findings were reported by Ricard et al. (2012) in the analysis of forty extreme precipitation events that occurred in southern France. They further pointed out that the synoptic and meso-scale patterns can have remarkable differences depending on the exact location of the event. Torrential rainfall events over southern Spain are in many cases either accompanied by a mid-tropospheric closed cyclonic circulation centred over the Gibraltar Strait, or by an elongated trough extending from North Atlantic/northern Europe (Romero et al. 1999). Heavy precipitation events in southern Switzerland are associated with meridionally elongated stratospheric intrusions over western Europe (Martius et al. 2008; Massacand et al. 1998). Funatsu et al. (2009) highlighted the presence of a well-developed low level cyclonic circulation over the Aegean during extreme precipitation events in Turkey.
Doswell III et al. (1998) investigated three extreme events over the western Mediterranean and highlighted some common factors (e.g., mid-tropospheric trough located westward with respect to the rainfall area) but also differences connected with deep convection and orographic lifting.

Most of the previous studies have focused on one region and/or on few case studies. A climatological analysis of upper-level synoptic-scale flow structures associated with extreme precipitation events in the whole Mediterranean basin is still missing.

Concerning the statistical characterisation of precipitation extremes, several studies have analysed daily precipitation time series recorded in the Mediterranean region (Lionello et al. 2012, and references therein) or in specific sub-areas (e.g., Yiou et al. 2008) by working in the frame of the Extreme Value Theory (e.g., Coles 2001). However, most of those studies have assumed temporal stationarity and spatial independence.

Here, we combine a statistical and a dynamical characterisation of precipitation extremes over the Mediterranean region by using recently proposed approaches for the identification of homogeneous (in terms of extremes, see next section) areas and the description of their non-stationary behaviour, and by exploring the upper level atmospheric dynamics prior to and during the selected events. The aim of this study is not to focus on some sites and/or single events, but to identify common upper-level flow features associated with precipitation extremes in homogeneous areas (in terms of precipitation extremes) of the Mediterranean region.

\section{Data and methods}

\subsection{Precipitation extremes}

A set of 108 daily precipitation time series from stations mainly located nearby coastal areas (Fig. 1) is used (Toreti 2010). The series cover almost 5 decades from 1961 to 2007 and were quality checked and tested against the presence of multiple inhomogeneities (Toreti et al. 2012). Here, daily extremes in three seasons (autumn: September-November, SON; winter: December-February, DJF; spring: March-May, MAM) are analysed in the frame of the Extreme Value Theory by applying an approach similar to the one proposed by Naveau et al. (2014). This procedure (when applied to large regions) requires an a priori identification of homogeneous (in terms of extremes) areas. Therefore a spatial classification method is first applied (Bernard et al. 2013). This method is based on a Partition Around Medoids (Kaufman and Rousseeuw 1990) with the dissimilarity measure given by the F-madogram (Cooley et al. 2006): 
Fig. 1 Location of the 108 weather stations. Colours indicate the homogeneous areas as identified by the clustering algorithm (grey: western Mediterranean; green: North Adriatic; blue: southern Italy/ Greece; red: western Turkey; yellow: south-western Turkey/ Cyprus; violet: Israel). The different shape of the grey, green and blue markers indicates the subdivision used for the analysis of the upper level atmospheric dynamics. The map at the bottom left corner provides a larger domain view of the region and its topography

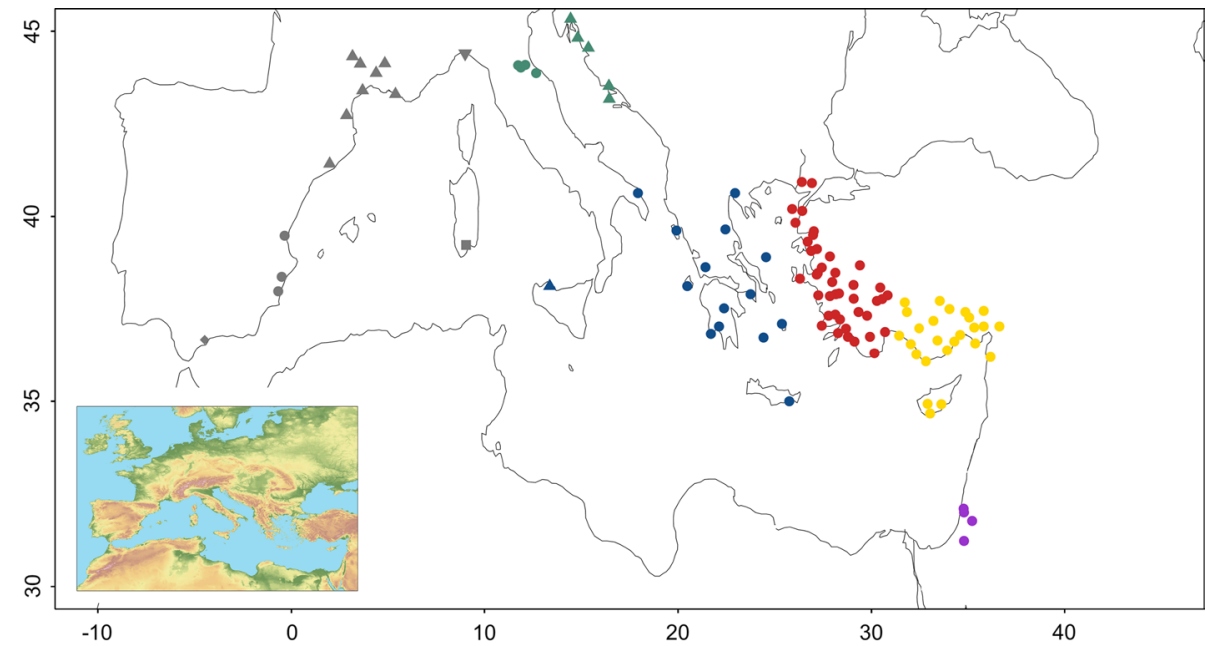

$d_{i j}=2^{-1} \mathbb{E}\left\{F_{i}\left(M_{i}\right)-F_{j}\left(M_{j}\right)\right\}=\frac{1}{2} \frac{V_{i j}(1,1)-1}{V_{i j}(1,1)+1}$,

where $i$ and $j$ represent two stations, $F_{i}$ and $F_{j}$ the marginal distributions of their (here, monthly) maxima $M_{i}$ and $M_{j}$, respectively. The second equality on the right side involves the extremal coefficient $V_{i j}(1,1)$, which gives information on the dependence of $M_{i}$ and $M_{j}$. If $V_{i j}(1,1)=1$ the two stations are independent and if $V_{i j}(1,1)=2$ they are dependent. $d$ therefore provides information on the degree of dependence between the extremes at the two stations, i.e.

$\mathbb{P}\left(M_{i} \leq u, M_{j} \leq u\right)=\left[\mathbb{P}\left(M_{i} \leq u\right) \mathbb{P}\left(M_{j} \leq u\right)\right]^{V_{i, j}(1,1) / 2}$

For more details on the method as well as on the estimation procedure the reader is referred to Bernard et al. (2013). The homogeneous areas identified with this method are shown in Fig. 1.

To each homogeneous area and for each season separately the following procedure is applied to characterise in a non-stationary framework the behaviour of daily excesses over a high threshold (here, the 90th percentile). Under convergency conditions (e.g., Coles 2001), the distribution of the excesses belongs to the Generalised Pareto family:

$G_{\sigma, \xi}(y)= \begin{cases}1-\left(1+\xi \frac{y}{\sigma}\right)^{-1 / \xi} & \text { if } \xi \neq 0, \\ 1-\exp \left(-\frac{y}{\sigma}\right) & \text { if } \xi=0 .\end{cases}$

Here, $y$ denotes the excesses and $\sigma$ and $\xi$ the (scale and shape, respectively) parameters to be estimated. In order to allow for non-stationarity, $\sigma=\sigma(\mathbf{x})$ where $\mathbf{x}$ is a 3-dimensional vector for the location in time and space. Since the estimation of $\xi$ is challenging and requires large sample sizes, we keep the shape parameter constant both in time and space within the same homogeneous area. This explains the need of an a priori identification of homogeneous areas.
In other words, we use data from all stations belonging to a homogeneous region for the entire time period to estimate $\xi$ that is assumed to be constant in time and equal for all station in the homogeneous area and to estimate $\sigma$ which changes over time and it is different for each station in the homogeneous area. The estimation is performed by combining generalised probability weighted moments and kernel regression (Naveau et al. 2014). This means that the parameters are not directly estimated, but they are derived from the estimation of the two generalised moments:

$\hat{\mu}_{r}(\mathbf{x})=\frac{1}{\sum_{i=1}^{n} K\left(\mathbf{x}-\mathbf{x}_{i}\right)} \sum_{i=1}^{n} K\left(\mathbf{x}-\mathbf{x}_{\pi_{i}}\right) Y\left(\mathbf{x}_{\pi_{i}}\right)\left(\frac{n-i}{n}\right)^{r}$,

with $r=1,1.5$ and where $K$ is a Kernel function, $\pi_{i}$ represents the estimated ordering of $Y\left(\mathbf{x}_{i}\right) / \mu_{0}\left(\mathbf{x}_{i}\right)$. Then, the two parameters can be simply calculated as follows:

$\hat{\sigma}(\mathbf{x})=\frac{2.5 \alpha}{2-2.5 \alpha} \hat{\mu}_{1}(\mathbf{x}), \quad \hat{\xi}=\frac{4-2.5^{2} \alpha}{2-2.5 \alpha}$

where $\alpha$ is the median of the ratio of $\hat{\mu}_{1.5}$ and $\hat{\mu}_{1}$. This implies that the estimation of $\sigma$ at a specific $\mathbf{x}^{\star}=\left(x^{\star}, y^{\star}, t^{\star}\right)$ is done by using and weighting data from sites in the neighbourhood of $\left(x^{\star}, y^{\star}\right)$ and from a time window centred at $t^{\star}$ (as defined by the Kernel function).

Finally, the return levels $z_{R}(\mathbf{x})$, expected to be exceeded on average once every $R$-years, are given by

$z_{R}(\mathbf{x})=u(\mathbf{x})+\hat{\sigma}(\mathbf{x}) \hat{\xi}^{-1}\left[\left(R \zeta_{u(\mathbf{x})}\right)^{\hat{\xi}}-1\right]$,

where $u$ is the time independent threshold and $\zeta_{u(\mathbf{x})}$ represents the intensity of the Poisson process giving the occurrence of the excesses. For further details on the procedure the reader is referred to Naveau et al. (2014). 


\subsection{Selection of extreme precipitation days and large-scale atmospheric dynamics}

As discussed in the introduction many heavy precipitation events are associated with distinct upper-level flow configurations such as for example troughs, i.e. positive PV anomalies, located upstream of the precipitation event. Here, this connection is explored for each identified area and season by selecting, for each station belonging to that area, all days characterised by a daily total precipitation amount exceeding a return period greater than 5 years. Since the estimated return levels are time dependent, the minimum return level of the series for each station is used as threshold. This means that the number of days selected per area, i.e. the sample size, is a function of the number of stations in the homogeneous area. For these days we then analyse the large-scale upper-level and low-level flow.

PV composites are calculated on the day of the events and up to 6 days before the selected events by using daily mean PV vertically averaged across 6 isentropic levels (320-345 K). The PV fields (expressed in PV unit, with 1 PVU defined as $1 \times 10^{-6} \mathrm{~m}^{2} \mathrm{~s}^{-1} \mathrm{~K} \mathrm{~kg}^{-1}$ ) are derived from ERA40 (1958-1978) and ERA-Interim (1979-2007) reanalyses (Uppala et al. 2005; Dee et al. 2011). The significance of the composites is assessed by using a Monte Carlo sampling approach with 500 members and deriving the 2nd and 98th percentiles of the 500 members. The Monte Carlo samples have the same seasonal distribution as the observed samples of the extreme precipitation events. Areas with PV values above (below) the 98th (2nd) percentile are considered significant.

\section{Results}

\subsection{Spatial and temporal variability of the extremes}

The 108 sites can be grouped into six homogeneous areas with respect to the statistical behaviour of precipitation extremes: western Mediterranean, North Adriatic, southern Italy/Greece, western Turkey, south-western Turkey/ Cyprus, and Israel (Fig. 1). Locations within each identified areas are characterised by a dependence of the extreme precipitation distributions as measured by the F-madogram (see the previous section and Bernard et al. 2013 for more details). For each area and season the statistical modelling of extremes is run. Since a non-stationary approach is applied, return levels are a function of both space and time. Figures 2, S1 and S2 show the maximum and the minimum 5 -year return levels during the 50-year time period, estimated for each site and season.

As expected, a large spatial variability characterises the Mediterranean region as a whole. Return values range from
$<40-177 \mathrm{~mm}$ in autumn, from $<30-130 \mathrm{~mm}$ in winter and from $<30-78 \mathrm{~mm}$ in spring. A very large spatial variability characterises the western-central Mediterranean in autumn, with the highest values of the basin recorded in the Gulf of Lion and the Gulf of Genoa and much lower values in the area of Marseilles. A more homogeneous spatial distribution and lower return values are found in the other areas and in the other two seasons.

The differences between the 50-year maxima and minima of the 5-year return values are usually $<25 \%$. Only few sites show larger differences (between 25 and $45 \%$ ); for instance, in the Gulf of Lion during autumn and in southern Spain and Italy during spring.

At the regional scale, higher spatial variability of both maxima and minima is found in the western-central Mediterranean, as shown in Figs. 3, S3 and S4 during all three seasons; while the other areas in the eastern Mediterranean show a much lower spatial variability. In the western Mediterranean, higher (lower) spatial (temporal) variability is estimated during winter and spring (Figs. S3 and S4), while in autumn the highest estimated values of return levels exhibit a lower spatial variability but higher temporal variability (Fig. 3). In the North Adriatic and over Greece/southern Italy, spring is characterised by a lower spatial variability (Fig. S4) and the highest return levels are found in autumn. Turkey and Cyprus are characterised by a much lower spatial variability (w.r.t. areas in the western-central Mediterranean) and by higher values of precipitation extremes during autumn and winter than in spring. Concerning the temporal differences, only western Turkey in autumn shows a remarkable difference between maxima and minima, namely approx. $13 \%$. Finally, Israel is affected by larger temporal differences (especially in autumn, approx. $34 \%$ ).

The identified spatial behaviour may be influenced by the spatial dimension of the areas as well as by the topography and the position within the basin.

\subsection{Upper-level dynamics}

In this section, the synoptic-scale flow structures associated with extreme precipitation events in the Mediterranean are presented for each region (from West to East) and for the three seasons. Discussed are mainly the structures on the day of the events and the significant upper-level flow structures, i.e. precursor signals, if present.

For the investigation of the upper-level dynamics, a further subdivision of the identified homogeneous areas, especially in the western Mediterranean, is needed. Indeed, first composites carried out by using the homogeneous areas have shown that the spatial complexity of the region, as well as the involved spatial distances, does not permit proper investigation of the upper-level dynamics without 
Fig. 2 5-year return levels minima (upper panel) and maxima (lower panel) estimated in autumn for the period 1961-2007. Values in $\mathrm{mm}$
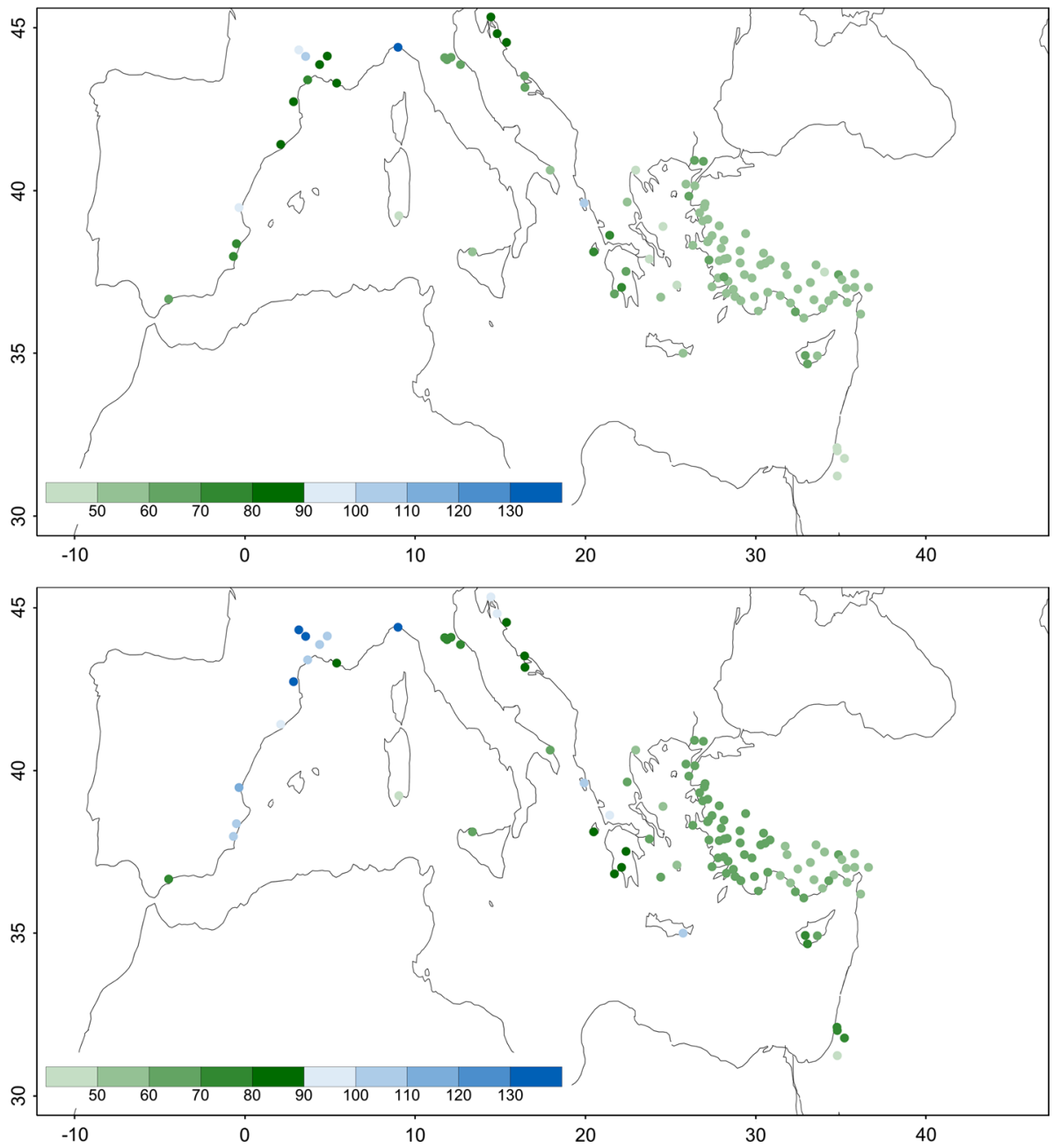

a further subdivision. We have therefore split the stations of the western Mediterranean into the following subgroups Gibraltar (note that the station is located slightly north-east of Gibraltar, but this name helps to easily localise the area within the domain), southern Spain, southern France (note that one station is located in Spain), Gulf of Genoa and Sardinia (Fig. 1). Stations in the North Adriatic are split into two groups: the Po Valley and the Balkans (Fig. 1). Finally, the group of Greece/southern Italy is subdivided into Sicily, Greece/Puglia (Fig. 1). A further subdivision is not needed for the other areas, i.e. western Turkey, southern Turkey/Cyprus, Israel. This additional subdivision has been done step-wise based on the results of the clustering routine, which indicates how strong or weak the connection of each cluster member to a specific cluster is and also based on previous studies in the region (e.g., Romero et al. 1999; Ricard et al. 2012; Toreti et al. 2010).

For all of these subareas, we show the composites of the upper-level flow during all identified extreme days (see the previous section and Table 1). The regional differences in the number of extreme days (Table 1) can be understood by considering the large differences in the number of stations and the choice of the minimum value of the estimated 5-year return level as a threshold for each station. This implies that results are only locally valid when the area under investigation contains a few (or even just one) stations and that they cannot be interpreted as representative of a larger region.

\subsection{Gibraltar}

Gibraltar is the most westerly area of this study. During autumn, on the day of the extreme events a south-east to north-west oriented upper-level PV trough is located over the eastern Atlantic and Portugal (Fig. 4a). Such an upperlevel PV anomaly can affect the low level wind field, as positive upper-level anomalies are associated with cyclonic wind fields. Indeed, a strong southwesterly flow at $850 \mathrm{hPa}$ over Gibraltar (>10 m/s) can be observed (Fig. 4a).

During spring, the upper-level flow on the day of extreme precipitation events in Gibraltar is characterised by a trough with south-west to north-east oriented axis located 


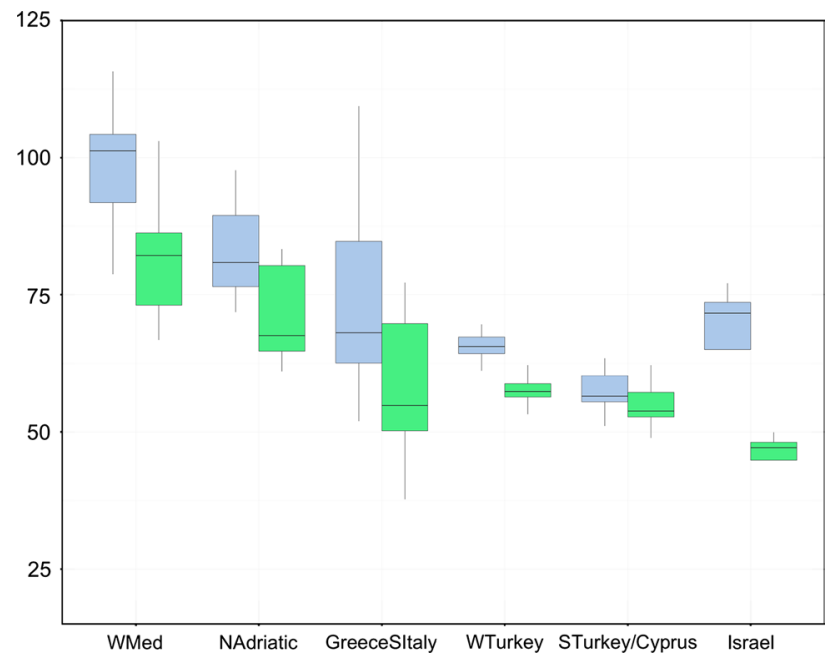

Fig. 3 Box-plots of the estimated 5-year return levels (mm) for each homogeneous area from 1961 to 2007 in autumn. The box plots summarize the values from all stations in a homogeneous region. The bold line in the centre of the box corresponds to the median returnlevel in the homogeneous region, the upper-and lower end of the box correspond to the 25th and 75th percentiles and the black lines indicate the highest and lowest value. Green indicates the minima and light blue the maxima

Table 1 Number of identified extreme precipitation days for each region and season

\begin{tabular}{lccc}
\hline Region (no. of stations) & Autumn & Winter & Spring \\
\hline Gibraltar (1) & 11 & 13 & 10 \\
Southern Spain (3) & 22 & 30 & 26 \\
Southern France (8) & 106 & 79 & 69 \\
Genoa (1) & 10 & 27 & 15 \\
Sardinia (1) & 13 & 15 & 20 \\
Sicily (1) & 12 & 23 & 12 \\
Po Valley (4) & 23 & 39 & 22 \\
Western Balkans (5) & 63 & 103 & 77 \\
Greece/Puglia (14) & 135 & 180 & 134 \\
Western Turkey (41) & 239 & 411 & 213 \\
Southern Turkey/ Cyprus (25) & 211 & 337 & 231 \\
Israel (4) & 23 & 95 & 28 \\
\hline
\end{tabular}

over the eastern Atlantic and Portugal (Fig. 4b). This orientation corresponds to the anticyclonic life-cycle of baroclinic waves (Thorncroft et al. 1993). The associated wind field at $850 \mathrm{hPa}$ results in strong south-westerly to southerly winds over Gibraltar. The PV trough is preceded by an upstream negative PV anomaly over the eastern Atlantic up to 3 days prior to the precipitation events (Fig. S5). Two days before the events the PV trough forms on the eastern flank of the negative PV anomaly and on the days before the event the PV trough is located over the eastern Atlantic.
Extreme precipitation events in Gibraltar during winter are associated with a south-west to north-east oriented trough over the north-western Iberian peninsula and the western Atlantic (extending further west than in spring, Fig. 4c). Along the eastern flank, a band of strong south-westerly winds extends from the western Atlantic into Gibraltar and southern Spain. Two days prior to the precipitation events, this trough forms over the eastern Atlantic and then moves southward (Fig. S5). For all seasons a statistically significant prominent positive upperlevel PV anomaly is identified to the west of Gibraltar. As discussed in the introduction, the role of such an upper-level trough in forcing precipitation is many-fold: its eastward propagation implies quasi-geostrophic air lifting on the eastern flank of the trough (Hoskins et al. 1985). Further on, the destabilization of the atmosphere by the upper-level PV (Hoskins et al. 1985) can result in enhanced convection (e.g., Funatsu and Waugh 2008). In addition, in all seasons strong southwesterly winds prevail over Gibraltar and, as stated by Wheeler (2007), winds from south/south-west can enhance local flow convergence in the area. This would result in the lifting of moist air masses.

\subsection{Southern Spain}

The autumn extreme precipitation events in south-eastern Spain are associated with a cut-off low located over southern Spain on the day of the events (Fig. 5a). In the lower troposphere, the cut-off is accompanied by a cyclonic flow and weak south-easterly winds over Andalusia (Fig. 5a). This flow can result in the advection of moist air from the east in the region around Valencia (Llasat et al. 2005). The main topographic features in south-eastern Spain are the Sierra Nevada and the Sierra Morena mountain ranges, both oriented in a SW-NE direction. Easterly/south-easterly winds have the potential to bring moist air from the Mediterranean towards these mountain ranges, and the interaction between moist air and the orography can result in extreme precipitation. Doswell III et al. (1998) presented a detailed diagnostic study of a heavy precipitation event that occurred in south-eastern Spain on 7-9 October 1992. The synoptic situation of that event was very similar to the identified composite upper level flow and the interaction between low-level easterly winds and the orography contributed to the enhancement of the rainfall.

The main upper-level flow feature during spring extreme precipitation events in south-eastern Spain is a PV trough located over the Iberian Peninsula accompanied by a PV ridge to the west over the east Atlantic and the North Sea (Fig. 5b). This upper-level flow is associated with a cyclonic flow over North Africa at $850 \mathrm{hPa}$ while over south-eastern Spain, weak easterly winds prevail. 

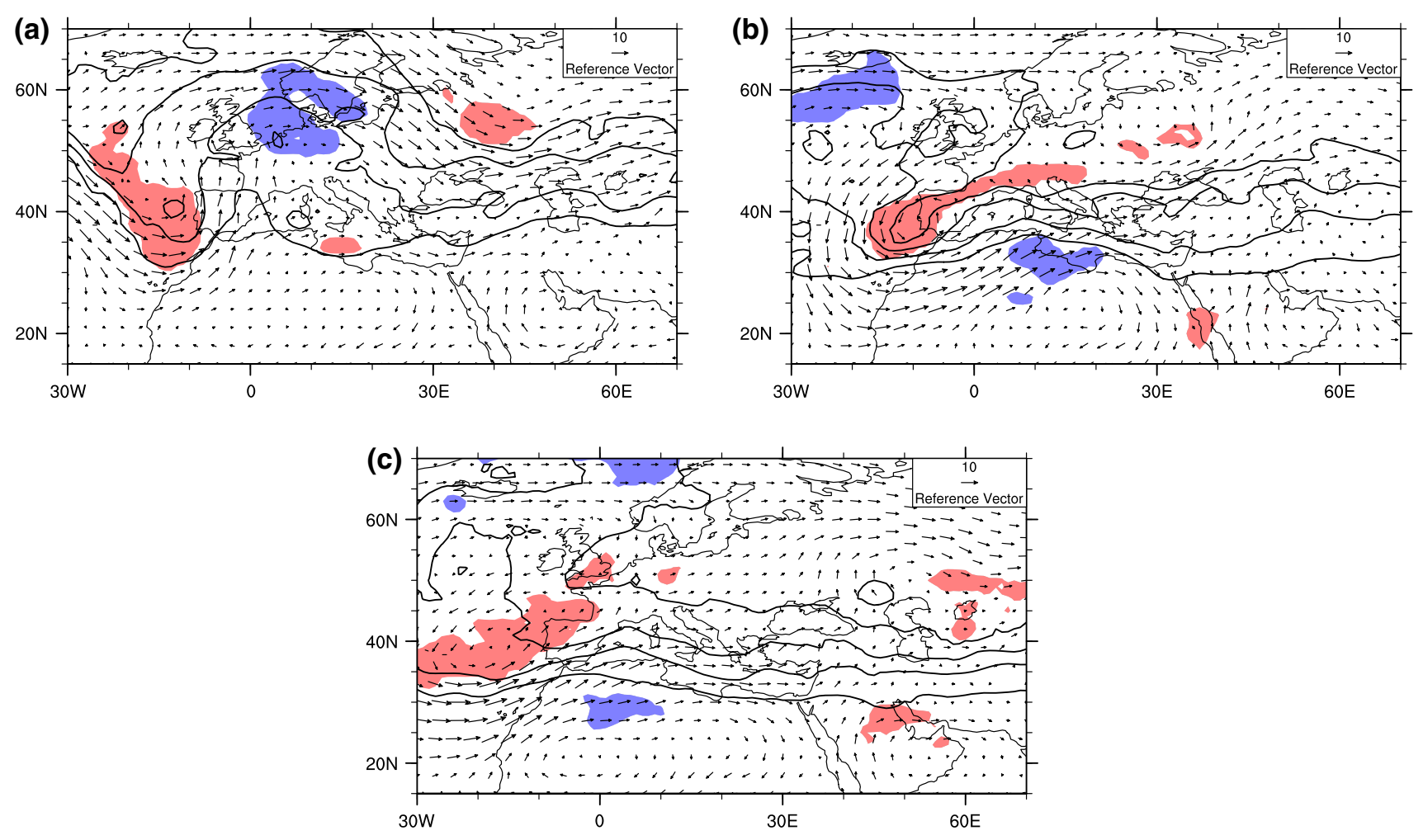

Fig. $4 \mathrm{PV}$ (solid black lines) and wind at $850 \mathrm{hPa}$ (vectors) composites associated with extreme precipitation events in Gibraltar. PV contour lines are from 2 to 6 PVU by 1 , while positive (negative) sig- nificant deviations of the composited PV are indicated by red (blue) colour. Wind at $850 \mathrm{hPa}$ is expressed in $\mathrm{ms}^{-1}$. a Represents autumn (SON) events; b spring (MAM) events; $\mathbf{c}$ winter (DJF) events
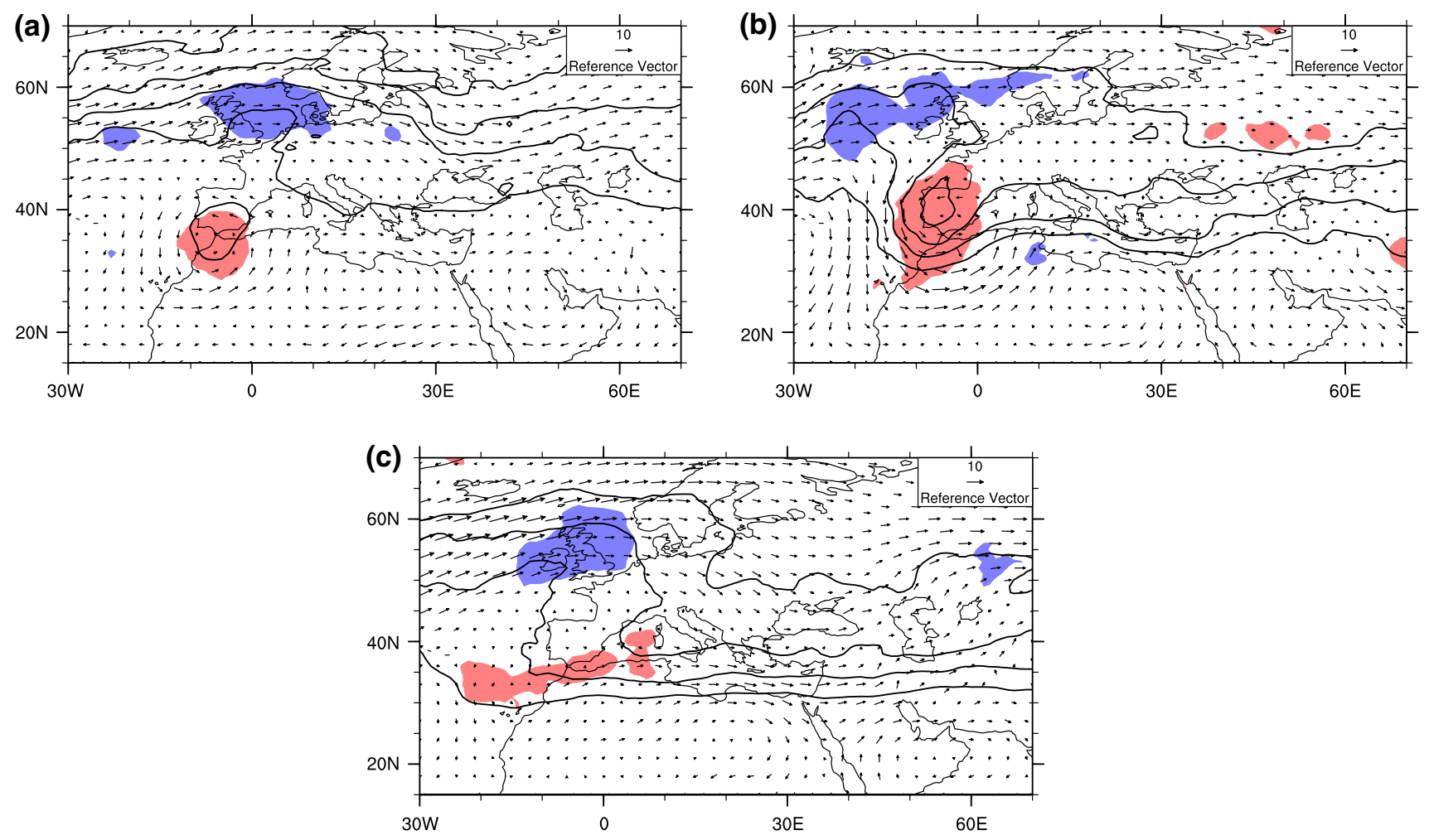

Fig. 5 As in Fig. 4 but for south-eastern Spain 

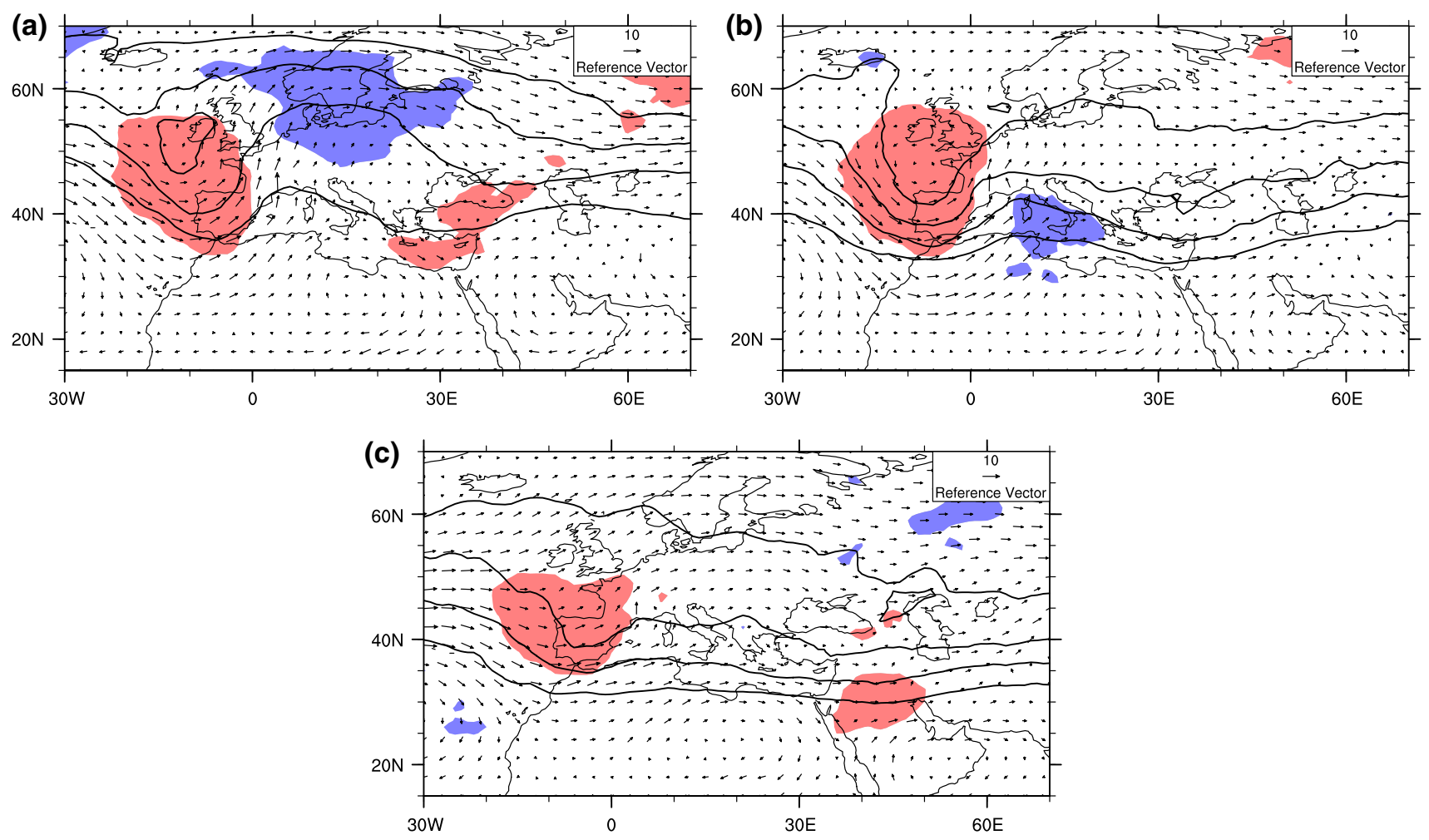

Fig. 6 As in Fig. 4 but for southern France

The characteristic upper-level structure during winter extreme precipitation events is a positive PV anomaly over the western Mediterranean and the eastern Atlantic (Fig. 5c). This anomaly forms 1 day before the events (Fig. S6). Weak winds are present over the western Mediterranean at $850 \mathrm{hPa}$ and weak winds over south-eastern Spain.

\subsection{Southern France}

Autumn extreme precipitation events in southern France are associated with a north-west to south-east oriented trough extending from west of the British Isles toward the Iberian Peninsula (Fig. 6a). This is in agreement with Ricard et al. (2012). This upper-level flow is associated with strong southerly winds at low-levels over France. Ducroq et al. (2008) studied three autumn extreme precipitation events in southern France and found that the interaction between southerly flow and the orography contributed to the enhancement of precipitation in the area. The formation of the identified trough takes 2 days and a significant negative PV anomaly, i.e. an anticyclonic flow anomaly, is present over the Baltic Sea 3 days prior to the events (Fig. S7).

A PV trough extending from the British Isles towards the Iberian peninsula oriented north-south is the distinct feature of the upper-level flow during spring extreme precipitation events in southern France (Fig. 6b). This area is located on its eastern flank and strong southerly/southwesterly winds prevail at $850 \mathrm{hPa}$. A significant positive PV anomaly, which amplifies meridionally and evolves into the trough, is present over the east Atlantic 2 days prior to the extreme events (Fig. S7).

The main upper-level flow feature concomitant with extreme precipitation events in winter is a low amplitude trough located over the west coast of Europe (Fig. 6c). In the lower troposphere the PV trough is accompanied by southerly/south-westerly winds over France. This low amplitude PV trough is preceded by statistically significant local precursor signals in the form of a positive PV anomaly over the eastern Atlantic (Fig. S7).

\subsection{Genoa}

Extreme precipitation events in Genoa in autumn are associated with a narrow, north-south oriented trough extending from Great Britain, across western France and the eastern Iberian Peninsula (Fig. 7a). Downstream of the trough, a low PV ridge is located over Italy and the Balkans. Strong southerly/south-westerly winds are present over Genoa. The upper-level flow structure and the low-level wind field are in agreement with the results of Rudari et al. (2005) and Rebora et al. (2013) for extreme precipitation events in the 

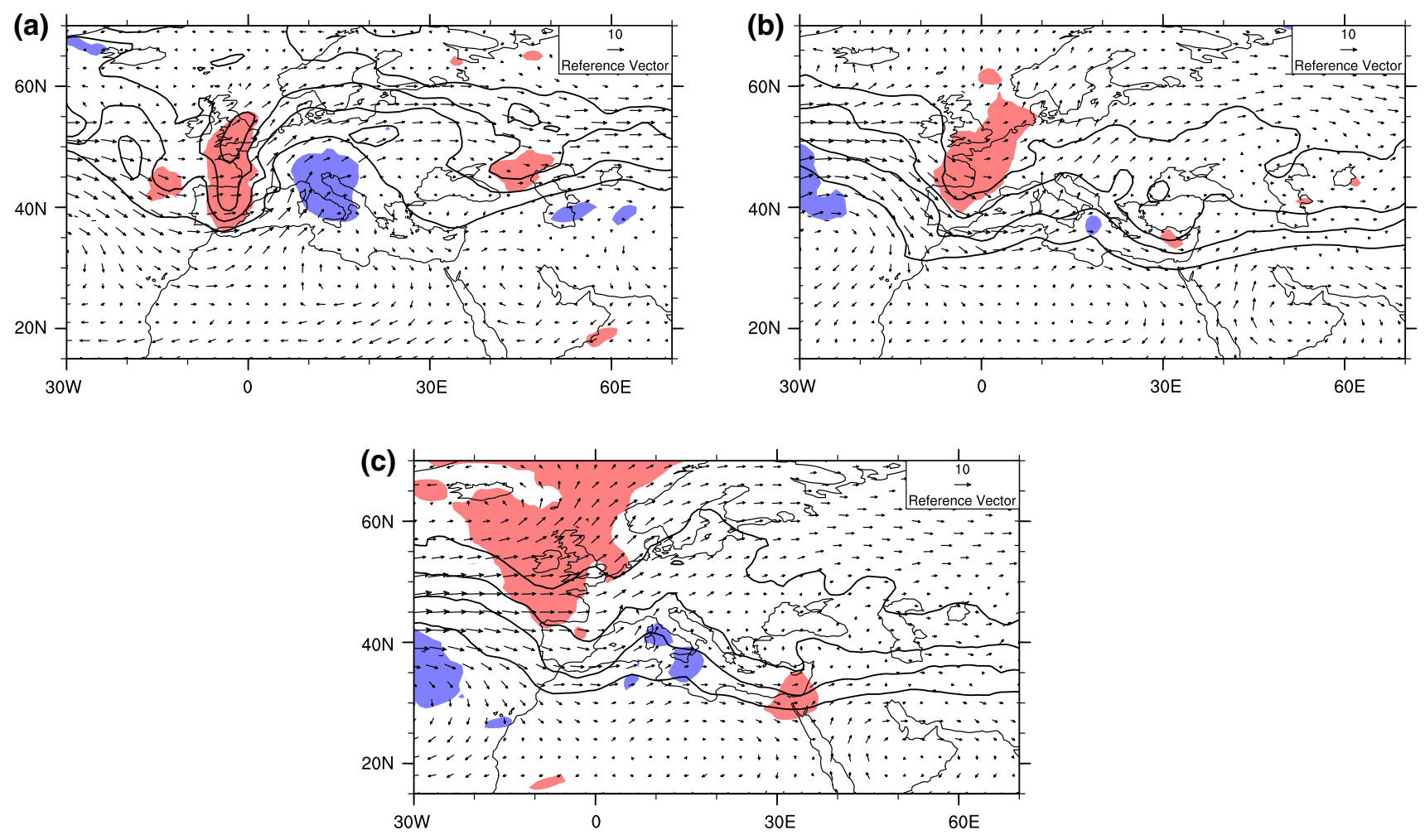

Fig. 7 As in Fig. 4 but for Genoa

Liguria region. Three days prior to the events a statistically significant low amplitude upper-level trough is located over the eastern Atlantic. Over the next days the PV trough moves eastwards over western Europe (not shown).

During spring and winter extreme precipitation events in Genoa, the upper-level flow is very similar. A broad PV trough is present over western Europe with Genoa located on its eastern flank (Fig. 7b, c). At $850 \mathrm{hPa}$ southerly/southwesterly winds prevail which are stronger in spring than in winter. The PV trough during winter events is preceded by a very strong ridge located over the North Atlantic 4 days before the events (Fig. S8). This strong ridge may contribute to the formation of the PV trough on its eastern side (Massacand et al. 2001).

\subsection{Sardinia}

A positive PV anomaly is located over the eastern Iberian Peninsula during autumn extreme precipitation events in Sardinia (Fig. 8a). Sardinia is located on the eastern flank of the anomaly where south-westerly winds prevail. Ehmele et al. (2015) performed sensitivity studies by removing and flattening the island of Sardinia. On days with strong synoptic forcing, the Sardinian orography played a significant role in determining the precipitation amount over Sardinia and Corsica.
During spring extreme precipitation events, a broad PV trough is located over the western Mediterranean and North Africa and strong southerly winds are prevailing over Sardinia (Fig. 8b). The PV trough can be traced back in time for 3 days, when the positive PV anomaly is located above western Atlantic and a significant negative PV anomaly is on its western flank (Fig. S9). Over the next days, the PV trough moves eastward and amplifies over the western Atlantic.

Extreme precipitation events in winter in Sardinia are associated with a positive upper-level PV anomaly located directly above the Island and embedded in a very broad south-west north-east oriented trough (extending from North Africa across the western Mediterranean; Fig. 8c). The wind over Sardinia at $850 \mathrm{hPa}$ is southerly and very weak. The formation of this trough prior to the extreme events is potentially assisted by an anomalously strong low PV ridge located over the North Sea and Scandinavia (Fig. S9).

\subsection{Sicily}

The main upper-level flow feature associated with extreme precipitation events in autumn in Sicily is a PV cut-off over Mediterranean that extends from $5^{\circ} \mathrm{E}$ to $20^{\circ} \mathrm{E}$ (Fig. 9a). In the lower troposphere, the cut-off is accompanied by a 

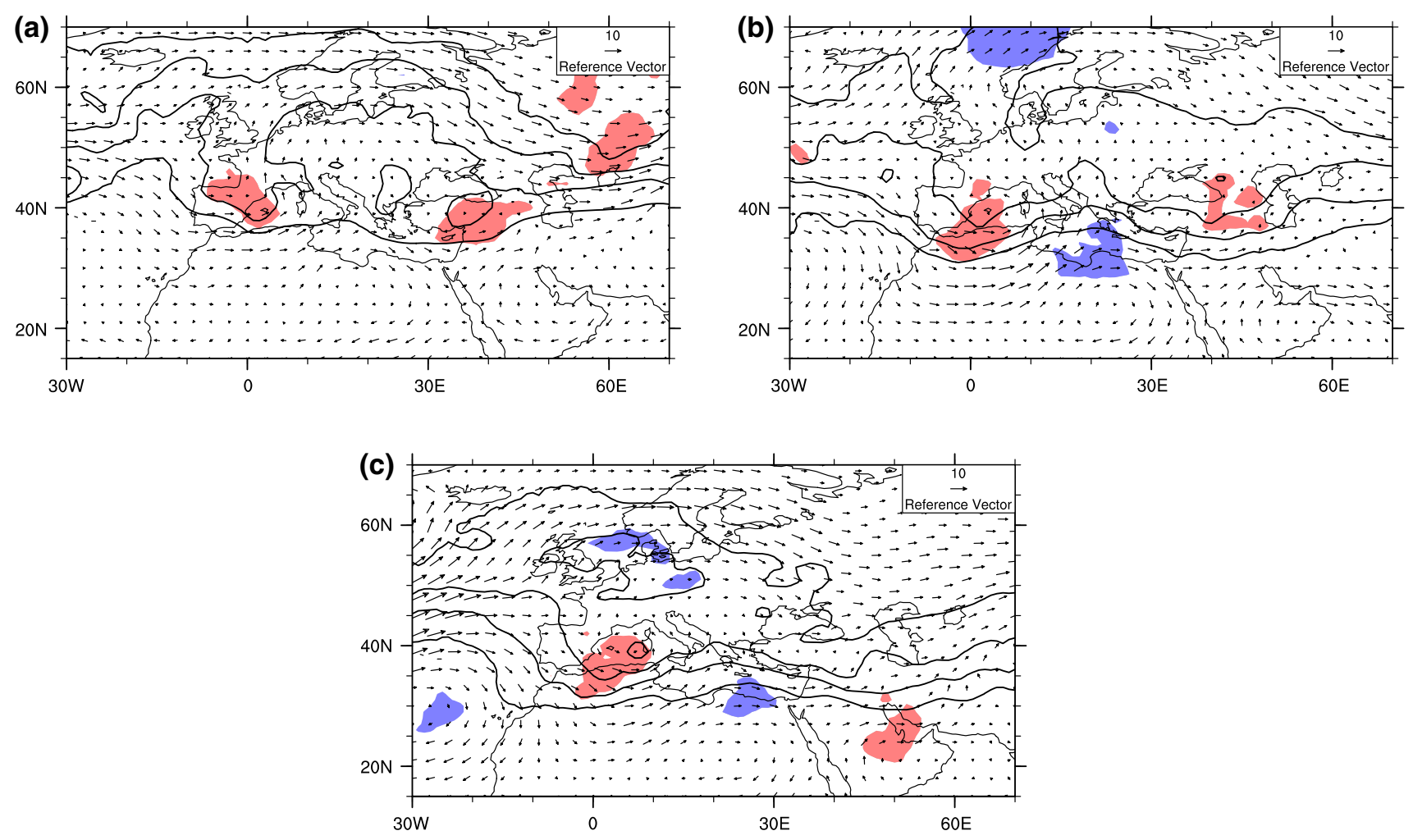

Fig. 8 As in Fig. 4 but for Sardinia
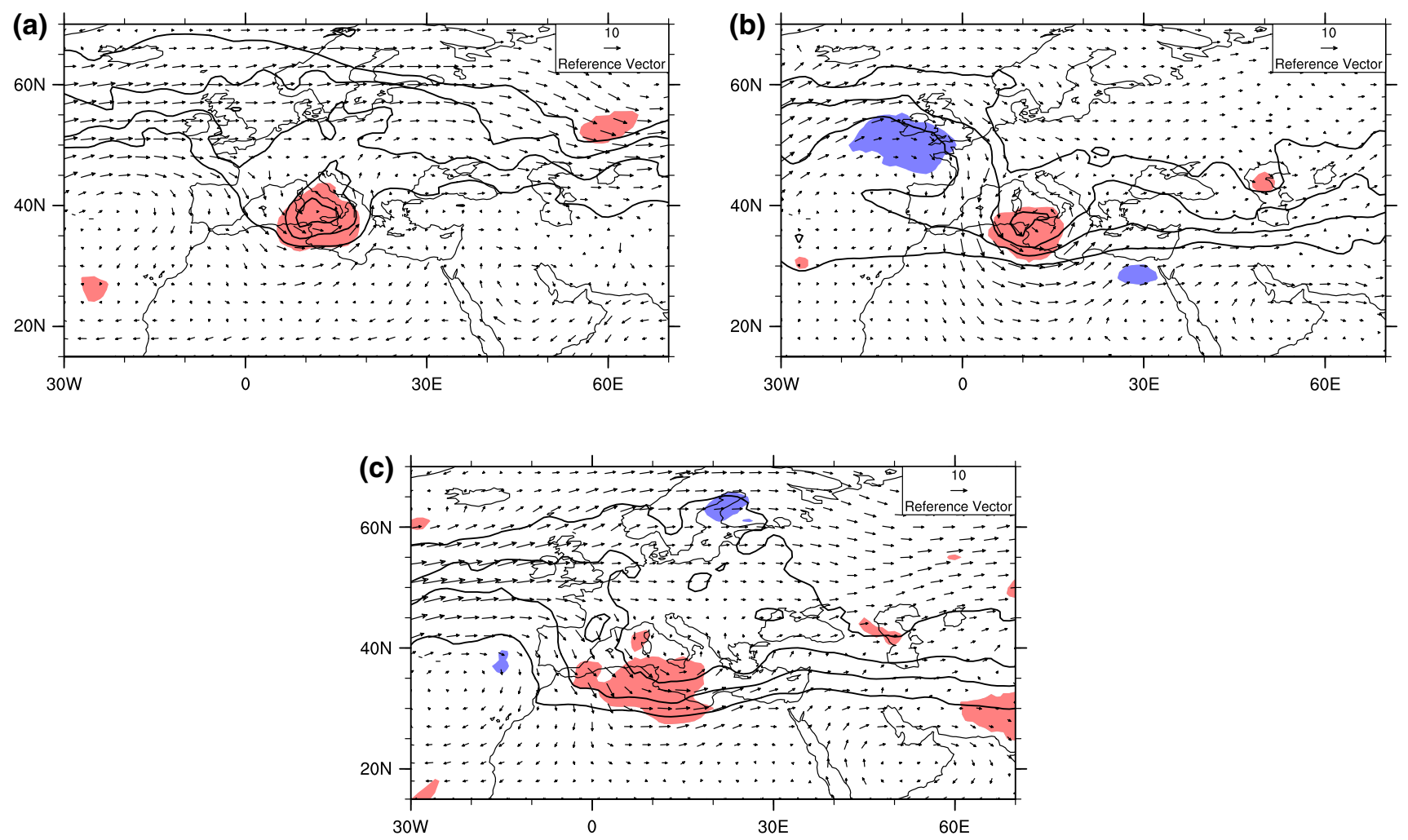

Fig. 9 As in Fig. 4 but for Sicily 

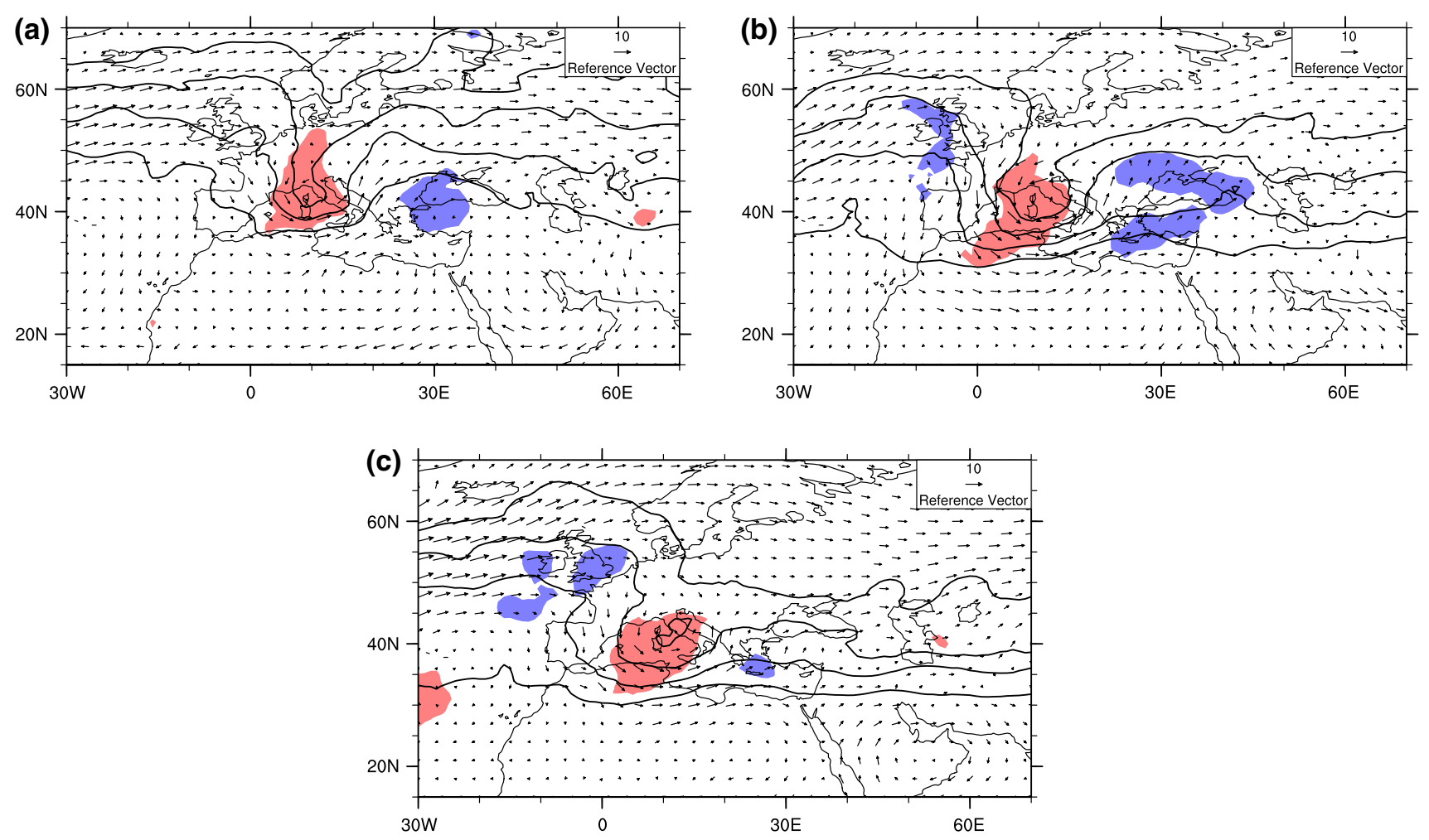

Fig. 10 As in Fig. 4 but for the Po Valley

cyclonic flow and weak winds over Sicily. A positive PV anomaly is present in the area already 2 days before the event downstream of an anomalously strong low PV ridge over the north-eastern Atlantic (Fig. S10).

During spring extreme precipitation events in Sicily, a PV trough is located slightly further to south-west compared with the location of the cut-off during the autumn events (Fig. 9b). Two days before the events a statistically significant positive PV anomaly is present above the western Mediterranean (Fig. S10).

Winter extreme precipitation events in Sicily are accompanied by a low amplitude, broad PV trough above North Africa and Sicily (Fig. 9c).

\subsection{Po Valley}

Extreme precipitation events in the Po Valley in autumn are associated with narrow north-south oriented troughs located over central Europe at approximately $10^{\circ} \mathrm{E}$ (Fig. 10a), slightly further east compared to those ones affecting Genoa. The troughs are slightly broader at the tip and there is a south-east north-west orientation of the eastern flank of these troughs directly over the Po Valley. Downstream of the troughs a low PV ridge is located over the western Black Sea and Turkey. At $850 \mathrm{hPa}$ weak easterly winds are present above the Po Valley. The formation of this trough takes 1 day (Fig. S11).

The upper level structures associated with extreme precipitation events during spring and winter are similar. A broader trough is located over Sardinia and north-western Italy (Fig. 10b, c). The associated cyclonic wind field at $850 \mathrm{hPa}$ provides weak easterly winds above the Po Valley. In winter a broad south-west north-east oriented trough is located over the western Mediterranean with its centre located slightly south of the Po Valley. The Po Valley is surrounded by mountains except in the east; thus, easterly and northeasterly winds can penetrate into the valley and potentially bring moist air from the Mediterranean towards the mountains and thus contribute to heavy precipitation.

\subsection{Western Balkans}

The main upper-level flow feature associated with autumn and spring extreme precipitation events in the western Balkans is a broad PV trough located over central Europe (Fig. 11a, b). The western Balkans are located along the eastern flank of the PV trough, where strong south-westerly winds prevail $(>10 \mathrm{~m} / \mathrm{s})$ at $850 \mathrm{hPa}$. There is a potential for an interaction between the strong moist south-westerly winds and NW-SE oriented mountain ranges in the area. 

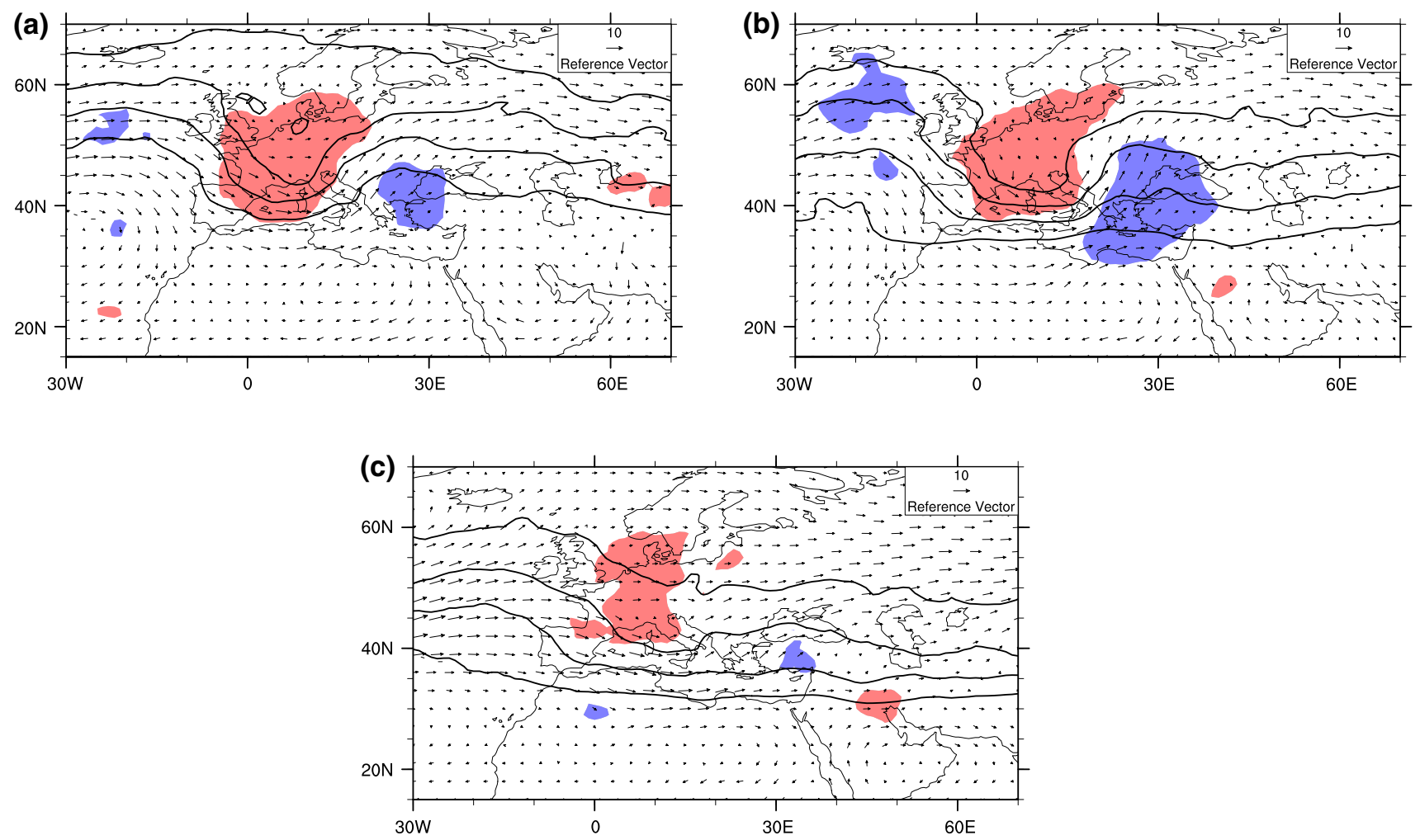

Fig. 11 As in Fig. 4 but for western Balkans

Two days before the events, the trough is preceded by a wave like upper-level flow pattern over the Atlantic basin in autumn and over the eastern Atlantic and Europe in spring (Fig. S12).

Winter extreme precipitation events are accompanied by a broad trough over central Europe which leads to southwesterly flow over the western Balkans (Fig. 11c). This positive $\mathrm{PV}$ anomaly is located over the British Isles 2 days prior to the extreme events and then moves south-eastward (Fig. S12).

\subsection{Greece/Puglia}

The upper-level flow structure associated with extreme precipitation events in Greece/Puglia is very similar in all three investigated seasons. A broad trough with a short meridional extent is located over Italy and the Balkans (Fig. 12a, b, c). An associated low-level cyclonic flow can be observed over Italy. In spring, the local PV maximum is located over southern Italy. This is in good agreement with Sindosi et al. (2015) who reported similar upper-level flow accompanied with southerly winds as typical synoptic situation associated with orographic precipitation in northwestern Greece during the cold season.

Although on the day of the events the upper-level flow structure is similar for all three seasons, the precursor signals are slightly different. In autumn and winter, a PV trough is located over central Europe 1 day before the events. In spring, this trough starts forming 2 days before the precipitation events and is itself preceded by an anomalously strong low PV ridge over the North Sea (Fig. S13).

\subsection{Western Turkey}

Extreme precipitation events in western Turkey are associated with similar upper-level structures during all three investigated seasons. A broad trough located over Greece and the Aegean Sea can be observed in Fig. 13, slightly further east compared to the troughs affecting Greece. Moreover, two negative PV anomalies are located on the western and eastern flank of the trough. The strongest negative PV anomalies are found for the spring events and the weakest for the winter events. Along the eastern flank of the trough, a band of strong westerly/south-westerly winds extends from the southern Mediterranean into western Turkey.

During autumn precipitation extremes, the PV trough is preceded by a negative PV anomaly over the western Mediterranean 4 days before the events. On the next days the trough forms over central Europe and amplifies (Fig. S14). Prior to the spring events a small positive PV anomaly is present over the eastern Mediterranean already 5 days before the events. On the next days 

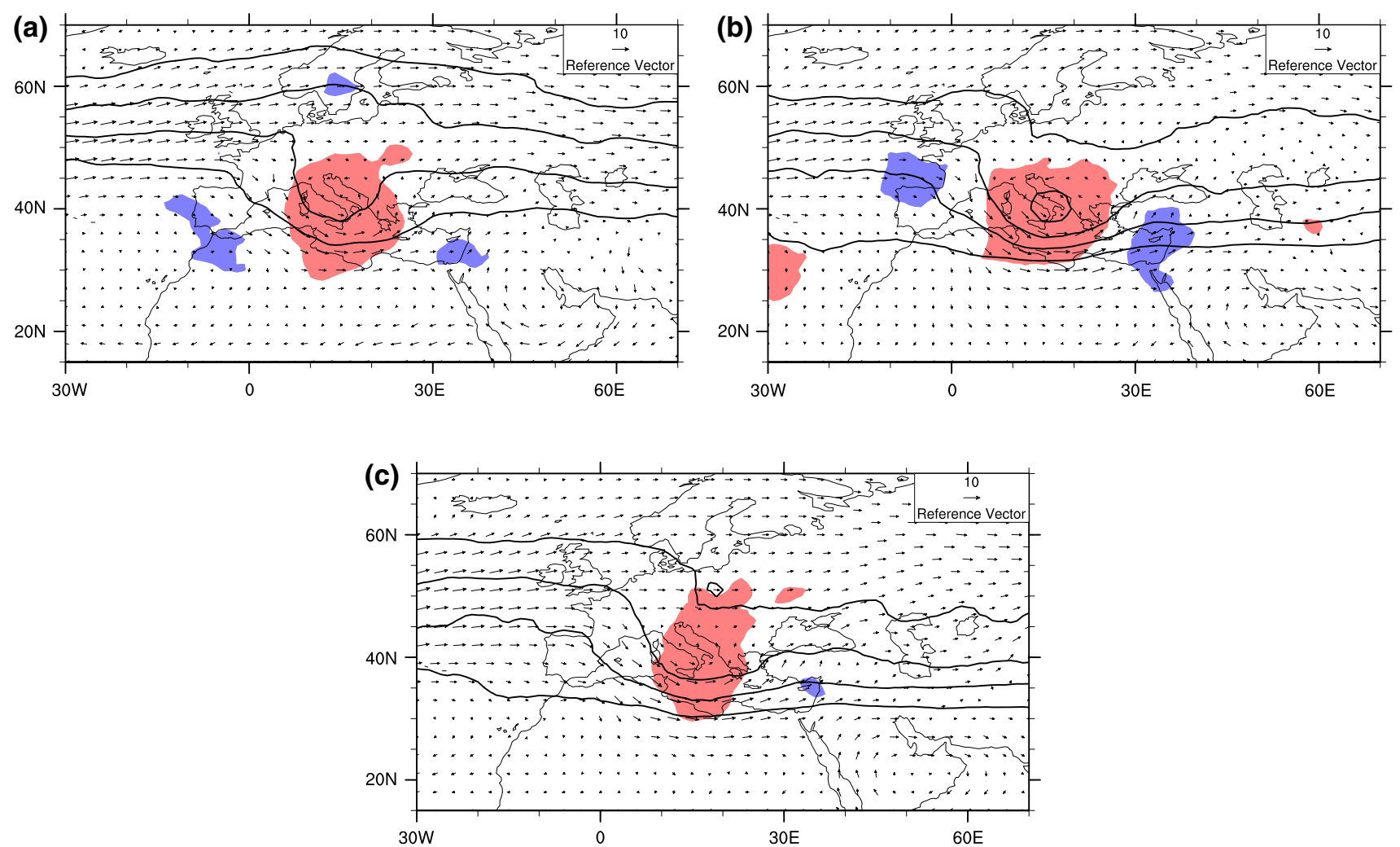

Fig. 12 As in Fig. 4 but for Greece and Puglia
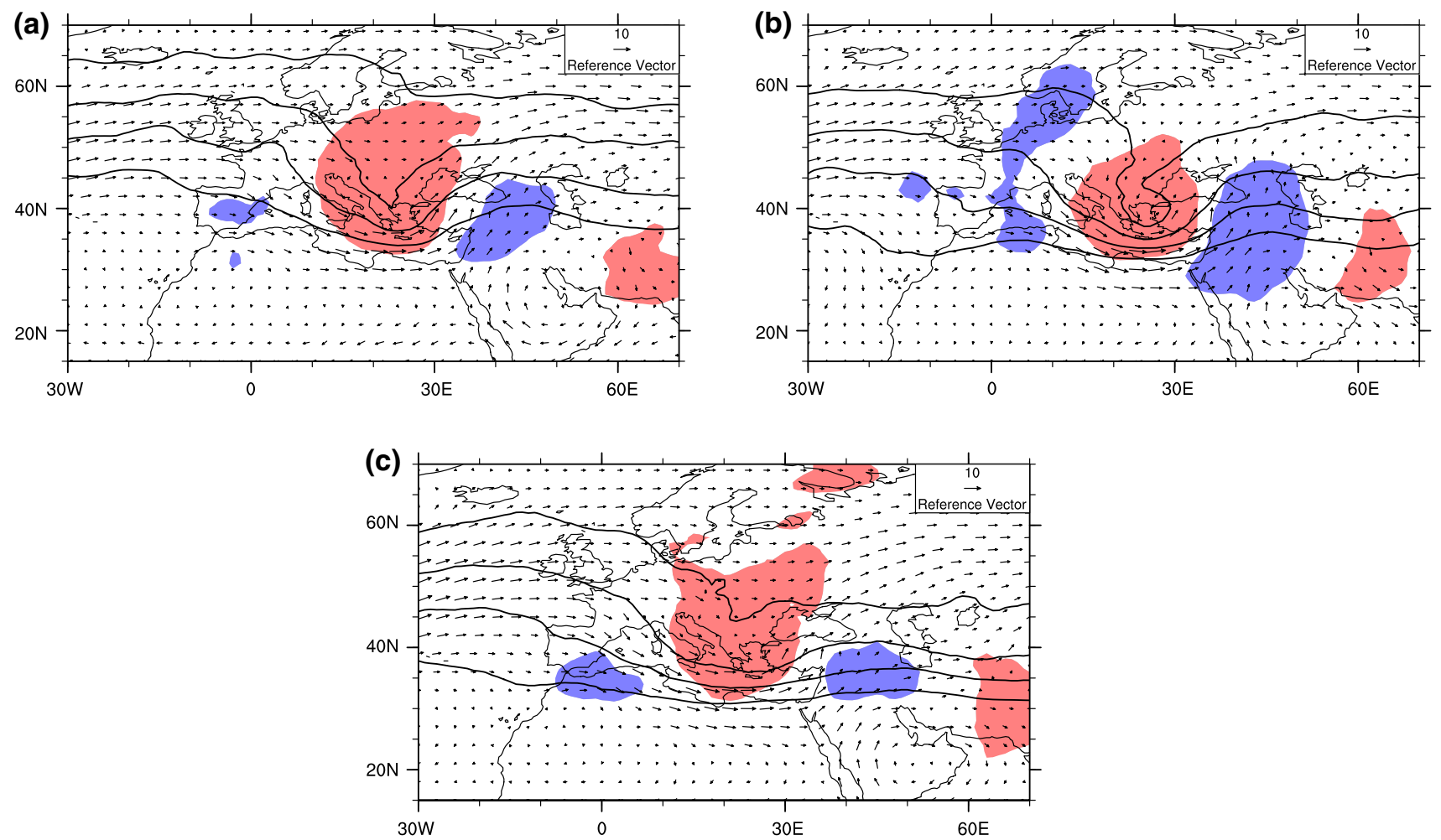

Fig. 13 As in Fig. 4 but for western Turkey 

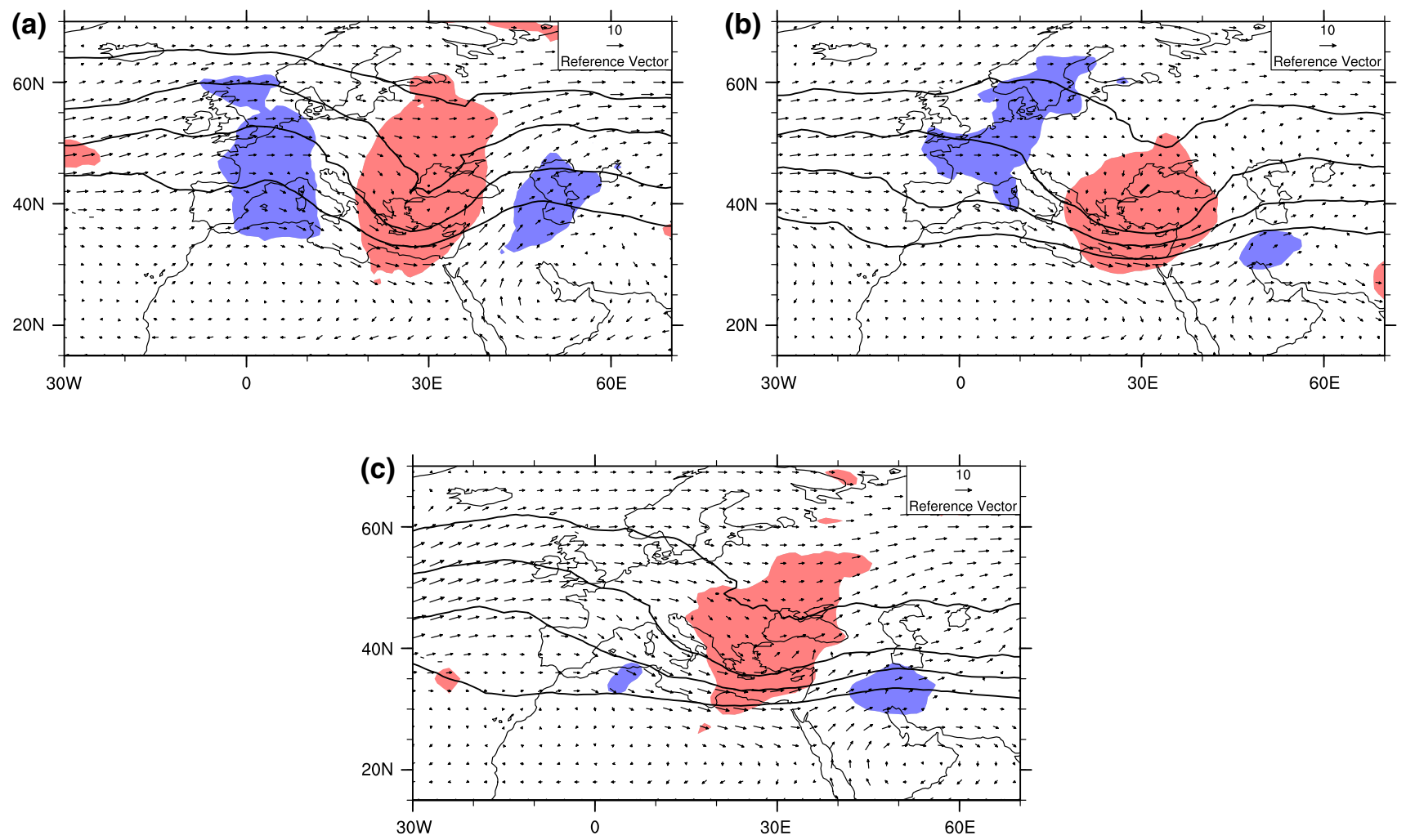

Fig. 14 As in Fig. 4 but for southern Turkey and Cyprus

a trough develops, amplifies, and remains almost stationary over the same area. The precursor signal for winter events can be traced back in time 3 days before the precipitation extremes. At this time, a positive PV anomaly is present over north-western Europe which over the next days moves eastward and amplifies over eastern Europe (Fig. S14).

\subsection{Southern Turkey/Cyprus}

The main upper-level flow structure during precipitation extremes in southern Turkey and Cyprus is also similar during all three seasons. A broad trough extends approximately from $10^{\circ} \mathrm{E}$ to $40^{\circ} \mathrm{E}$ (Fig. 14a, b, c). The trough is accompanied by two negative PV anomalies on both sides. The negative PV anomalies are strongest during autumn and weakest during winter. In autumn, the associated flow at lower levels has a strong south-westerly component over Cyprus and southern Turkey. In spring and winter, the low amplitude trough is accompanied by westerly/south-westerly winds over Cyprus and southern Turkey. The flow above southern Turkey is very weak in spring. The southern coast of Turkey is characterised by steep topography which is an obstacle for moist air masses coming from the south and this results in orographic precipitation. For all three investigated seasons, the upper-level upstream precursor signals prior to precipitation extremes in southern Turkey and Cyprus are very similar to the precursor signals prior to extreme events in western Turkey (Fig. S15).

\subsection{Israel}

Israel is the most easterly region in our domain. Extreme precipitation events in Israel during autumn are associated with a relatively broad south-west/north-east oriented upper-level trough located over the Black Sea and Turkey on the day of the events and a strong low PV ridge upstream over western and central Europe (Fig. 15a). Strong winds are present at $850 \mathrm{hPa}$ over Europe and strong westerly to south-westerly winds prevail over Israel. The trough over the Black Sea develops during a 3 day period prior to the events (Fig. S16).

A wave like upper-level flow pattern over the Mediterranean basin is present during spring precipitation extremes in Israel (Fig. 15b). A PV trough is located over the eastern Mediterranean accompanied by cyclonic flow at 850 $\mathrm{hPa}$, resulting in strong westerly/south-westerly winds over Israel. A wave like upper-level structure is present over the Mediterranean 1 day before the events and could be part of the wave train signal described by Feldstein and Dayan (2008) propagating along the subtropical jet over North Africa prior to heavy precipitation events in Israel. 

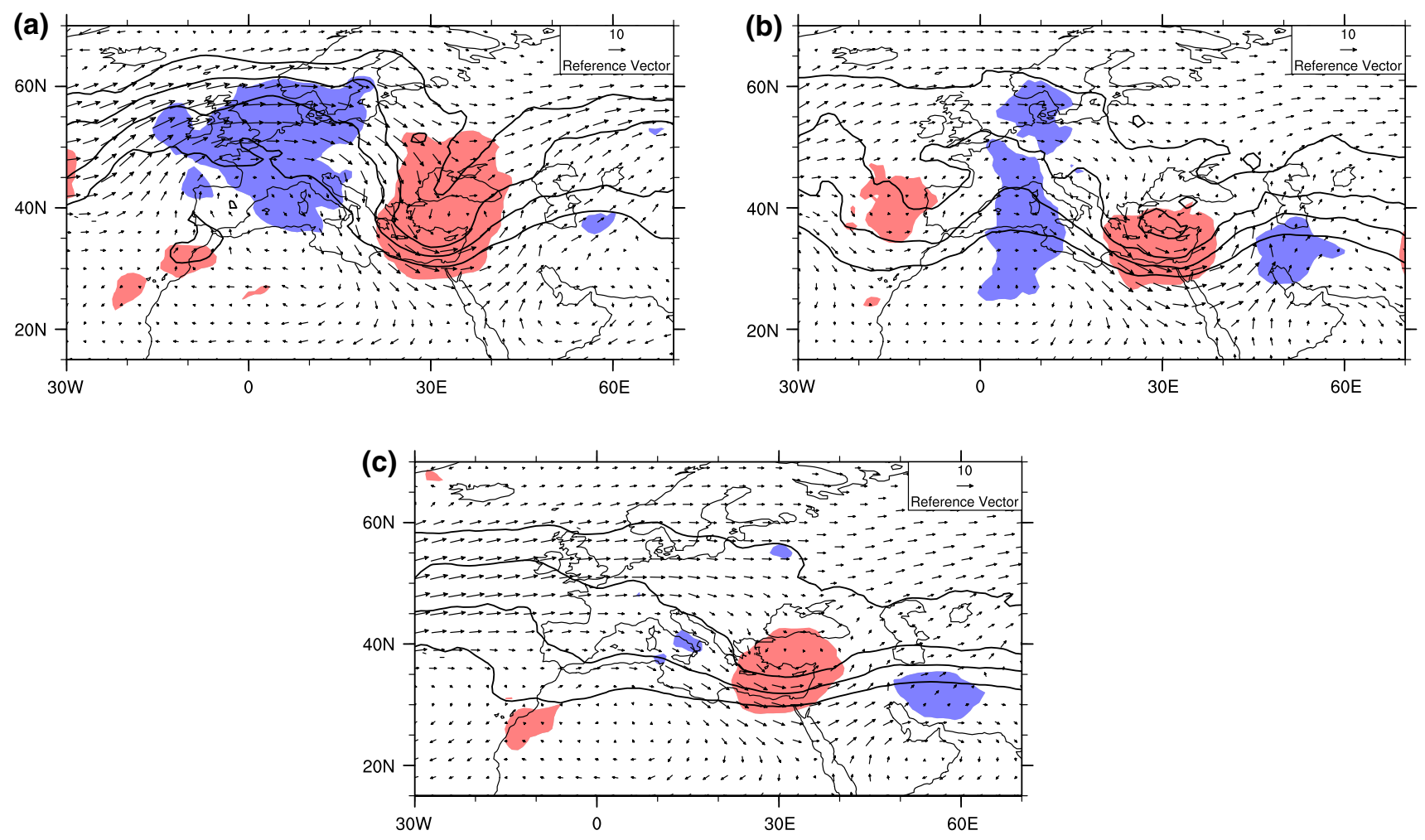

Fig. 15 As in Fig. 4 but for Israel

The main upper-level feature in winter extreme events in this area is a low amplitude PV trough over the eastern Mediterranean (Fig. 15c). At $850 \mathrm{hPa}$, the flow over Israel is westerly to south-westerly. Ziv et al. (2005) studied an extreme winter precipitation event over southern Israel and reported a similar synoptic situation with quasi-geostrophic lifting in the area associated with the upstream trough.

\section{Discussion and conclusion}

In this study, a non-stationary statistical characterisation of daily precipitation extremes over the Mediterranean basin is presented. Large spatial variability (especially in the western Mediterranean) characterises the estimated 5-year return levels. Extremes are non-stationary and the temporal variability of the 5-year return levels of precipitation does not show a homogeneous behaviour across the Mediterranean basin. In most areas the difference between maximum and minimum 5 -year return levels is smaller than $25 \%$ of the maximum value, exceptions are some stations in the western Mediterranean. More studies, both improving the applied statistical methods and investigating the link between the temporal variability of the extremes and the large scale dynamics, for instance connected with the North Atlantic Oscillation and the Atlantic Multidecadal Oscillation, are needed.
It is worth underlining that intrinsic uncertainties affect the applied statistical procedures, especially in areas with a limited spatial station density. Indeed, both the classification and estimation steps are data-demanding (especially in a non-stationary context with a classification based on extremes' dependence) and, thus, a better coverage of the Mediterranean region would surely help in the characterisation and understanding of precipitation extremes. For the areas with a very small number of stations, e.g. Sardinia, results have a limited spatial representativeness. Besides data limitations also the relatively coarse resolution of the reanalysis influences the results. The spatial and temporal resolution of the reanalysis makes impossible to discuss the potentially important contribution of meso-scale processes (e.g., Mesoscale Convective Systems) to the development of precipitation extremes.

The analysis of the common synoptic-scale structures associated with extreme precipitation events has revealed that for all areas significant synoptic-scale upper-level flow structures can be identified for all areas on the day of the events. Typically, the structures are positive upper-level PV anomalies located west of the area where the precipitation event occurred. The specific shape of these anomalies varies substantially between areas, ranging from broad and shallow troughs to elongated and narrow troughs and cut-offs. The identified structures are in agreement with 
those reported by Raveh-Rubin and Wernli (2015) in their analysis of the top ten extreme precipitation events in the Mediterranean. It is important to underline that the identified upper-level structures represent (due to the design of the analysis and the aims of this study) the mean spatial configurations, i.e. the most important flow pattern for each region. This means that if two or more preferred flow patterns can result in extreme precipitation in one area only the pattern representative for most cases will be identified. At the single event scale, spatial differences (e.g., in the position and extension of the trough) can be expected. Furthermore, some events mainly triggered by meso-scale processes are likely to be not significantly associated with an upper-level signal.

Indeed in some areas the upper-level flow signal is less distinct, e.g., over Sicily and Sardinia. This points to a larger case-to-case variability and/or the important role of meso-scale processes for triggering the precipitation events. When the upper-level flow structures associated with the precipitation extremes are spatially homogeneous in one season, a statistically significant signal can clearly emerge. Higher spatial variability and/or a dominant role of the meso-scale processes, can prevent the emergence of a statistically significant signal at the synoptic scale. The relatively coarse spatial and temporal resolution of the reanalysis data sets does not resolve meso- and smaller-scale flow structures, which are very important for triggering extreme precipitation in some regions (e.g., Doswell III et al. 1998; Hernandez et al. 1998). It is important to point out that the meso-scale convective systems can be associated with upper-level flow structures, e.g., weak upper-level troughs that help to destabilise the atmosphere (e.g., Hoskins et al. 1985; Russell et al. 2008, 2012). However, strong convection can also occur without any upper-level forcing.

The results highlight the important role of synoptic-scale flow in the formation of extreme precipitation events. The exact role of the upper-level flow can vary from quasi-geostrophic forcing of ascent, over the forcing of moist air against topography, to the local destabilisation of the atmosphere. A detailed quantification of these processes is beyond the scope of this study, however, it is worth to highlight that, in many areas, the flow is oriented against the local topography and hence the interaction of moist air with the topography might be of central importance for the precipitation extremes. Next steps in quantifying this interaction would entail a detailed analysis of the lower-tropospheric moisture transport.

Upper-level precursor signals can be identified 2-3 days before precipitation extremes (and even earlier in some areas and seasons). This implies a certain degree of predictability of precipitation extremes. The seasonal variations of these precursor signals are on the one hand due to seasonal variations of the background flow, i.e. in the location, the strength and the coherence of the waveguide along which the precursor waves propagate (Martius et al. 2008), on the other hand they are due to seasonal changes in the processes and synoptic-structures that trigger the precipitation extremes. A statistically significant signal points to homogeneous upper-level flow structures associated with the precipitation extremes, if the variability is large and / or mesoscale processes are dominant, the signal is not statistically significant.

Finally, the identified lower spatio-temporal variability of eastern Mediterranean extremes is reflected by more homogeneous and well-defined upper-level atmospheric structures. While, the differences in the upper-level flow structures highlighted in the western Mediterranean contribute to the higher spatio-temporal variability of precipitation extremes in the area.

Acknowledgments We thank two referees for their comments and suggestions that helped to improve this study. P. Giannakaki acknowledges funding by the Swiss Science Foundation, Project Nr. 200021-137543.

Open Access This article is distributed under the terms of the Creative Commons Attribution 4.0 International License (http://creativecommons.org/licenses/by/4.0/), which permits unrestricted use, distribution, and reproduction in any medium, provided you give appropriate credit to the original author(s) and the source, provide a link to the Creative Commons license, and indicate if changes were made.

\section{References}

Bernard E, Naveau P, Vrac M (2013) Clustering of maxima: spatial dependencies among heavy rainfall in France. J Clim 26:7929-7937

Coles S (2001) An introduction to statistical modeling of extreme values. Springer, Berlin

Cooley D, Naveau P, Poncet P (2006) Dependence in probability and statistics. Springer, chap Variograms for spatial max-stable random fields

Davison AC, Padoan SA, Ribatet M (2012) Statistical modeling of spatial extremes. Stat Sci 27:161-186

Dee DP et al (2011) The ERA-interim reanalysis: configuration and performance of the data assimilation system. Q J R Meteorol Soc 137:553-597

Doswell CA III, Ramis C, Romero R, Alonso S (1998) A diagnostic study of three heavy precipitation episodes in the western Mediterranean region. Weather Forecast 13:102-124

Ducroq V, Nuissier O, Ricard D, Lebeaupin C, Thouvenin T (2008) A numerical study of three catastrophic precipitating events over southern France. ii: Mesoscale triggering and stationary factors. Q J R Meteorol Soc 134:131-145

Ehmele F, Barthlott C, Corsmeier U (2015) The influence of Sardinia on Corsican rainfall in the western Mediterranean Sea: A numerical sensitivity study. Atmos Res 153:451-464

Feldstein SB, Dayan U (2008) Circumglobal teleconnections and wave packets associated with israeli winter precipitation. Q J R Meteorol Soc 134:455-467 
Funatsu BM, Waugh DW (2008) Connections between potential vorticity intrusions and convection in the eastern tropical Pacific. J Atmos Sci 65(3):987-1002

Funatsu BM, Claud C, Chaboureau JP (2009) Comparison between the large-scale environments of moderate and intense precipitating systems in the Mediterranean region. Mon Weather Rev 137:3933-3959

Giorgi F (2006) Climate change hot-spots. Geophys Res Lett 33(L08):707

Hernandez E, Cana L, Diaz J, Garcia R, Gimeno L (1998) Mesoscale convective complexes over the western Mediterranean area during 1990-1994. Meteorol Atmos Phys 68:1-12

Hoskins BJ, McIntyre ME, Robertson AW (1985) On the use and significance of isentropic potential vorticity maps. Q J R Meteorol Soc 111:877-946

Kaufman L, Rousseeuw P (1990) Finding groups in data: an introduction to cluster analysis. Wiley, New Jersey

Kharin VV, Zwiers FW, Zhang X, Wehner M (2013) Changes in temperature and precipitation extremes in the cmip5 ensemble. Clim Dyn 119:345-357

Knutti R, Sedláček J (2012) Robustness and uncertainties in the new cmip5 climate model projections. Nat Clim Change 3:369-373

Lionello P, Abrantes F, Congedi L, Dulac F, Gacic M, Gomis D, Goodess C, Hoff H, Kutiel H, Luterbacher J, Planton S, Reale M, Schröder K, Struglia MV, Toreti A, Tsimplis M, Ulbrich U, Xoplaki E (2012) The climate of the Mediterranean Region: from the past to the future. Elsevier, chap Mediterranean climate - background information

Llasat MC, Barriendos M, Barrera A, Rigo T (2005) Floods in Catalonia (NE Spain) since the 14th century. Climatological and meteorological aspects from historical documentary sources and old instrumental records. J Hydrol 313:32-47

Martius O, Schwierz C, Davies HC (2008) Far-upstream precursors of heavy precipitation events on the alpine south-side. Q J R Meteorol Soc 134:417-428

Massacand AC, Wernli H, Davies HC (1998) Heavy precipitation on the alpine south side: an upper level precursor. Geophys Res Lett 25:1435-1438

Massacand AC, Wernli H, Davies HC (2001) Influence of upstream diabatic heating upon an Alpine event of heavy precipitation. Mon Weather Rev 129:2822-2828

Naveau P, Toreti A, Smith I, Xoplaki E (2014) A fast nonparametric spatio-temporal regression scheme for heavy precipitation. Wat Resour Res 50:4011-4017

Nuissier O, Ducroq V, Ricard D, Lebeaupin C, Anquetin S (2008) A numerical study of three catastrophic precipitating evens over southern France. i: Nnumerical framework and synoptic ingredients. Q J Roy Meteorol Soc 134:111-130

Raveh-Rubin S, Wernli H (2015) Large-scale wind and precipitation extremes in the Mediterranean - a climatological analysis for 1979-2012. Q J R Meteorol Soc. doi:10.1002/qj.2531

Rebora N, Molini L, Casella E, Comellas A, Fiori E, Pignone F, Siccardi F, Silvestro F, Tanelli S, Parodi A (2013) Extreme rainfall in the Mediterranean: What can we learn from observations? J Hydrometeorol 14:906-922

Ricard D, Ducroq V, Auger L (2012) A climatology of the mesoscale environment associated with heavily precipitating events over a northwestern Mediterranean area. J Appl Meteorol Clim $51: 468-488$

Romero R, Sumner G, Ramis C, Genovés A (1999) A classification of the atmospheric circulation patterns producing significant daily rainfall in the Spanish Mediterranean area. Int J Climatol 19:765-785

Rudari R, Entekhabi D, Roth G (2005) Large-scale atmospheric patterns associated with mesoscale features leading to extreme precipitation events in Northwestern Italy. Adv Water Resour 28:601-614

Russell A, Vaughan G, Norton EG, Morcrette CJ, Browning KA, Blyth AM (2008) Convective inhibition beneath an upper-level PV anomaly. Q J R Meteorol Soc 134:371-383

Russell A, Vaughan G, Norton EG (2012) Large-scale potential vorticity anomalies and deep convection. Q J R Meteorol Soc 138:1627-1639

Sindosi OA, Bartzokas A, Kotroni V, Lagouvardos K (2015) Influence of orography on precipitation amount and distribution in NW Greece; a case study. Atmos Res 152:105-122

Thorncroft CD, Hoskins JB, McIntyre MF (1993) Two paradigms of baroclinic-wave life-cycle behaviour. Q J R Meteorol Soc 119:17-55

Toreti A (2010) Extreme events in the Mediterranean: analysis and dynamics. Ph.D. thesis, University of Bern

Toreti A, Xoplaki E, Maraun D, Kuglitsch FG, Wanner H, Luterbacher J (2010) Characterisation of extreme winter precipitation in Mediterranean coastal sites and associated anomalous atmospheric circulation patterns. Nat Hazards Earth Sys 10:1037-1050

Toreti A, Kuglitsch FG, Xoplaki E, Luterbacher J (2012) A novel approach for the detection of inhomogeneities affecting climate time series. J Appl Meteorol Clim 51:317-326

Toreti A, Naveau P, Zampieri M, Schindler A, Scoccimarro E, Xoplaki E, Dijkstra HA, Gualdi S, Luterbacher J (2013) Projections of global changes in precipitation extremes from cmip5 models. Geophys Res Lett 40:4887-4892

Uppala SM et al (2005) The ERA-40 reanalysis. Q J R Meteorol Soc 131:2961-3012

Wheeler D (2007) The Gibraltar climatic record: part 2-precipitation. Weather 62:99-104

Yiou P, Goubanova K, Li ZX, Nogaj M (2008) Weather regime dependence of extreme value statistics for summer temperature and precipitation. Nonlinear Proc Geoph 15:365-378

Ziv B, Dayan U, Sharon D (2005) A mid-winter, tropical extreme flood-producing storm in southern Israel: synoptic scale analysis. Meteorol Atmos Phys 88:53-63 